\title{
The Significance of CD3 Marker in the Diagnosis of Celiac Disease
}

\author{
Saja Hashim Hammo*, Professor Wahda Mohammad Taib Al-Nuaimy ${ }^{\star \star}$, Mohammed A. Hayawi ${ }^{\star \star \star}$ \\ *Postgraduate Student, Department of Pathology, College of Medicicn, University of Mosul , **Department of \\ Pathology College of Medicine , University of Mosul , ${ }^{\star \star \star}$ Nursing College, University of Mosul, Mosul, Iraq \\ Correspondence: saja.hashim.abdulqader@gmail.com
}

(Ann Coll Med Mosul 2020; 42 (2):99-108).

Received: 18 ${ }^{\text {th }}$ Oct. 2020; Accepted: $6^{\text {th }}$ Dec. 2020.

\begin{abstract}
Background: Celiac disease is a common, permanent and reversible health problem of small intestine occurring all over the world in genetically predisposed individuals and in combination with other environmental factors. It causes chronic inflammation of small intestine which is of autoimmune origin. The histopathological features of Celiac disease in duodenal biopsy was stated according to the modified Marsh classification. The immunohistochemical application of CD3 marker in duodenal biopsy could facilitate the count and the distribution of intraepithelial lymphocytes along the villi, which is regarded as a key for the correct diagnosis of Celiac disease in early stages ( Marsh 1).
\end{abstract}

Objectives: This study was conveyed to correlate the significance of CD3 immunohistochemical expression of intraepithelial lymphocytic population to histopathological changes in Celiac disease, to identify the distribution of CD3 marker along the villi (crescendo or decrescendo) and (diffuse or patchy ) in duodenal biopsy and to delineate the age and sex of Celiac disease in our locality.

Materials and methods: This prospective and retrospective case series study was carried out on 100 cases of endoscopically obtained duodenal biopsies. Data obtained from archives of the pathology department, at AL-Jamhory, AL-Khansaa and AL-Salam Teaching Hospitals/ Mosul city, and collected in a period spanning from January 2019 to May 2020. The information included age, sex and duodenal biopsy location. Modified Marsh classification was assessed histologically and immunohistochemically.

Results: In a total of 100 duodenal samples, patients age was ranged 1 to 69 years (mean age of 20.74 years), with a female to male ratio (2.2:1).

By applying modified Marsh classification: Marsh 0 was detected in $8 \%$ of the cases, Marsh 1 in $30 \%$ of the cases, Marsh 2 in 10\% of the cases, while Marsh 3 a in $20 \%$ of the cases, Marsh $3 \mathrm{~b}$ in $17 \%$ of the cases, Marsh $3 \mathrm{c}$ in 15\% of the cases and Marsh 4 in $0 \%$. Immunohistochemical expression of CD3 in the sampled cases i.e. CD3 $+\geq 30 / 100$ epithelial cells was detected in $79 \%$ of the cases. There was a statistically significant difference between $\mathrm{CD} 3+$ immunohistochemical study and modified Marsh classification by Hematoxylin \& Eosin $(P$ Value $<0.001)$ for detection of intraepithelial lymphocytosis.

Conclusion: There is a significant relationship between the count of CD3+ T-lymphocytes per 100 epithelial cells and the histopathological changes in the duodenal biopsy according to modified Marsh classification. So, the immunohistochemical expression of CD3 in intraepithelial T-lymphocyte could lead to a definite assessment in $43.3 \%$ of the sampled cases with Marsh type 1. All the positive cases are of crescendo pattern of distribution of CD3+ T-lymphocytes as the distribution is more important than the actual count and they distributed diffusely except that associated with Helicobacter pylori infection observed with patchy distribution. In addition to that, The IHC expression of CD3+ marker provides a hint about the distribution of CD3+ marker within the lymphocyte whether global surface or clonal surface and intracytoplasmic to diagnose Refractory Celiac disease.

On the other hand, females were more affected than males with $\mathrm{CeD}$ and there is a significant relationship between the gender of the sampled cases and the histopathological changes in the duodenal biopsy.

The disease can be diagnosed at any age and there is no significant relationship between the age distribution of the sampled cases and the histopathological changes in the duodenal biopsy.

Keywords: Celiac disease, intraepithelial lymphocytes, modified Marsh classification, CD3, Immunohistochemistry.

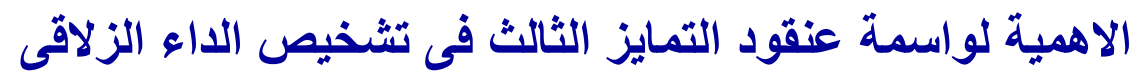




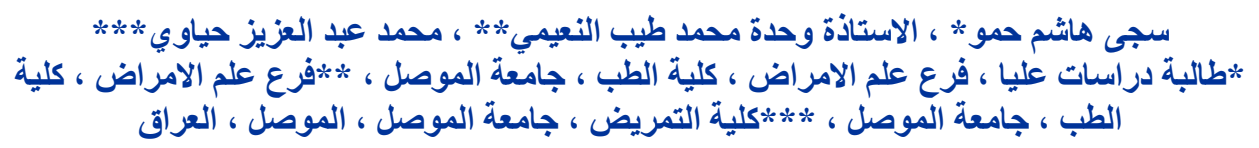

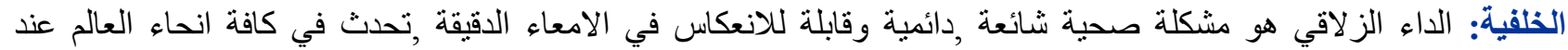

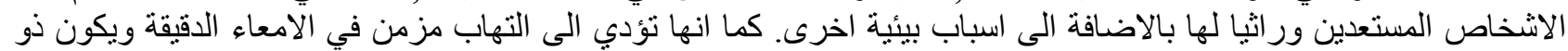

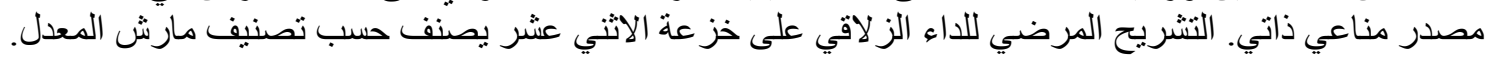

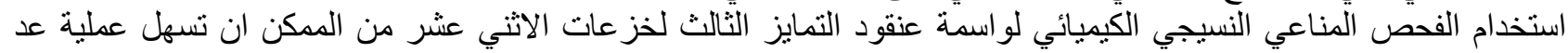

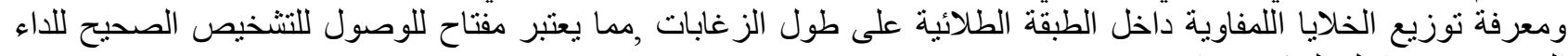

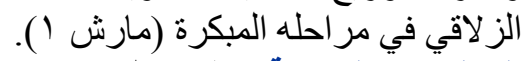

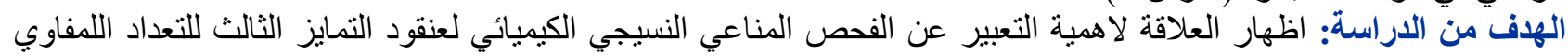

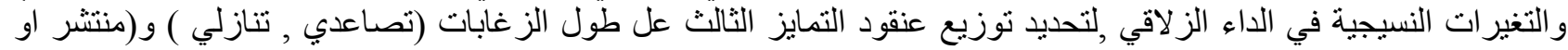

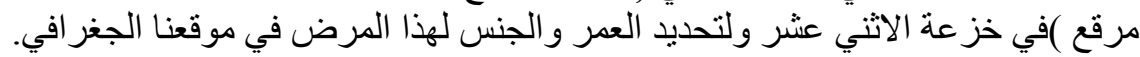

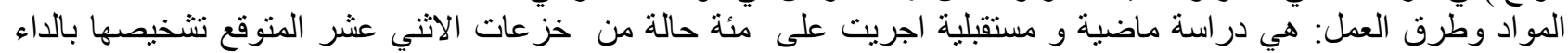

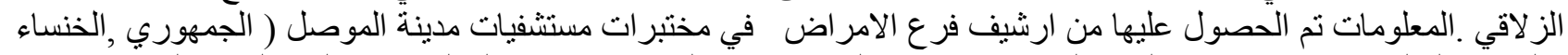

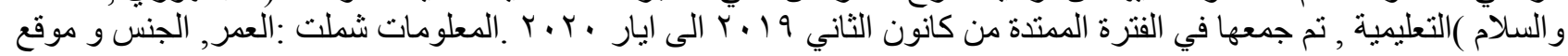

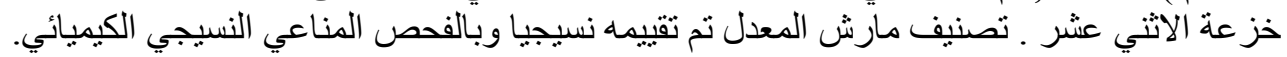

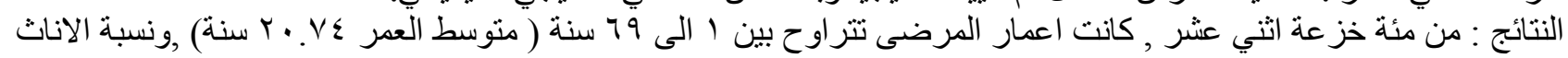

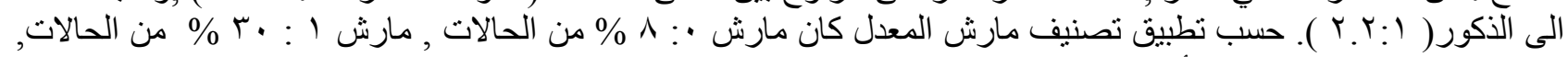

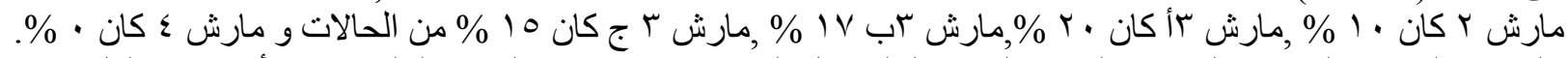

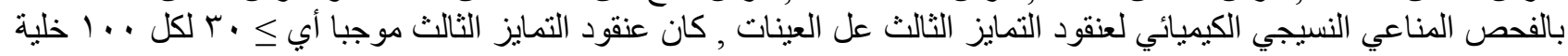

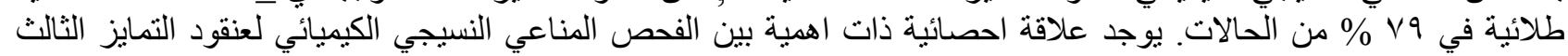

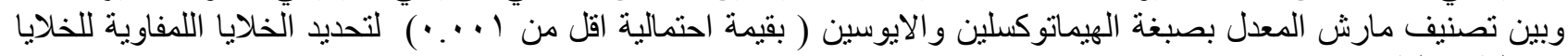
بين الطبقة الطلائية.

الاستنتاجات: يوجد علاقة احصائية ذات الهمية بين عدئ الطين الخلايا اللمفاوية تي الموجبة لعنقود التمايز الثالث لكل مئة خلية طلائية

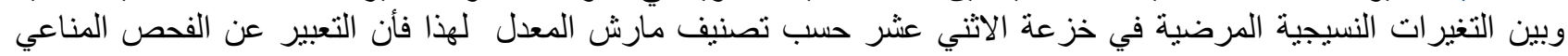

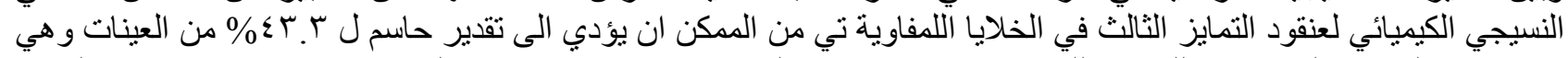

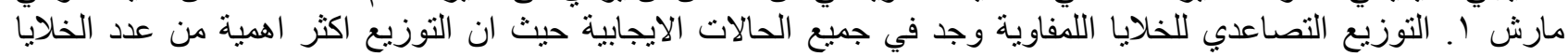

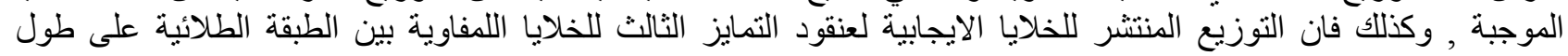

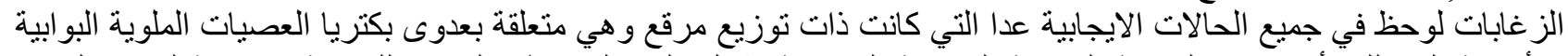

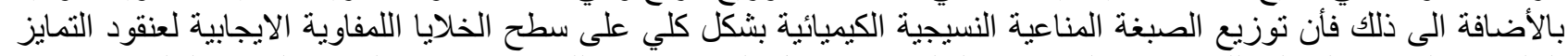

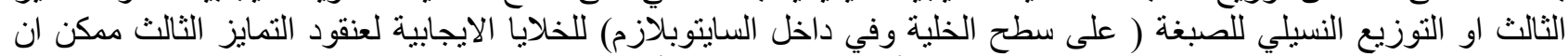

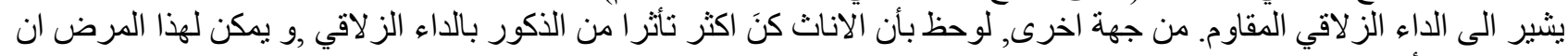
يشخص في أي عمر.

الكلمات المفتاحية : الداء الزلاقي, الخلايا اللمفاوية خلال الطبقة الطلائية, تصنيف مارش المعدل, عنقود التمايز الثالث, الفحص المناعي النسيجي الكيميائي.

\section{INTRODUCTION}

Celiac disease (CeD) is a common, permanent and reversible health problem of small intestine occurring all over the world in genetically predisposed individuals and in combination with other environmental factors. It causes chronic inflammation of small intestine which is of autoimmune origin. Celiac disease has a wide spectrum of clinical features gastrointestinal and non-gastrointestinal manifestations. It affects both children and adult age groups ${ }^{1}$.

There are many methods to diagnose Celiac disease like serological tests, upper gastrointestinal endoscopy, histopathological features of the biopsies and others ${ }^{2-4}$. 
Histopathological features depend on the number and distribution of intraepithelial lymphocytes (IELs), presence or absence of crypt hyperplasia and villous atrophy. Then a conclusion stated according to the modified Marsh classification $^{5-7}$.

Sometimes there is increase in intraepithelial lymphocytes infiltration without crypt hyperplasia and villous atrophy in duodenal biopsies (Marsh 1) which is not specific for Celiac disease and other causes should be excluded like infections by Helicobacter pylori bacteria, Giardia lamblia, Tropheryma whippeli, Cryptosporidium and many others ${ }^{8-10}$.

When immunohistochemistry (IHC) is used for CD3 in Celiac disease, it facilitates counting of IELs and noticing the distribution along the villi (crescendo or decrescendo) and (diffuse or patchy), also it provides a hint about the distribution of the staining (surface or intracytoplasmic) to diagnose Refractory Celiac disease and differentiate between its two types as type II may precede to enteropathy associated Tcell lymphoma (EATL) ${ }^{3,11-14}$.

\section{MATERIALS AND METHODS Patient Selection}

This study is a retrospective and prospective case series study which was performed on 100 consequentive cases suspected to have Celiac disease over a period of 16 months started from January 2019 to May 2020. A tissue block of each case was chosen for histopathology and $\mathrm{IHC}$.

This work was maintained a routine protocol approval to access the clinicopathological data from archives of the department of pathology at AL-Jamhory, AL-Khansaa and AL-Salam Teaching Hospitals in Mosul city, and these included: age, sex and duodenal biopsy location.

\section{Histopathological and IHC Staining}

Use of formalin fixed, paraffin embedded blocks for each case. Once the slides prepared by two methods: H\&E and IHC stains, prepared for target retrieval prior to IHC procedures, using Dako Target Retrieval Solution (10x) that prepared by diluting the concentrate $1: 10$ in distilled or deionized water together with water bath based Dako PT Link, for deparaffinization, re-hydration and epitope retrieval to increase staining intensity with many primary antibodies by unmasking of the antigen. Then staining by automated staining instrument which is Dako autostainer link 48 slide stainer that used for efficient IHC staining and thermoscientific CD3 early T-cell marker for qualitative $\mathrm{IHC}$ that is of clone designation SP7. Positive controls as well as negative controls run simultaneously using the same protocol as the patient's specimens.

The CD3 marker was optimized using tonsils ( $T$ lymphocytes in the interfollicular areas and dispersed T-cells in the mantle zones and within the germinal centers) as a positive control which displays at least a moderate to strong and distinct membranous staining reaction, with no staining must be seen in the germinal center B-cells which was considered as negative control.

\section{Scoring and Analysis:}

All cases are microscopically examined for interpretation of histopathological and IHC stains. So each case stained by H\&E designated according to modified Marsh Oberhuber classification of histologic findings in $\mathrm{CeD}^{5-7}$. stage 0 normal ( preinfiltrative mucosa). stage 1 lymphocytic enteritis (infiltrative). stage 2 lymphocytic enteritis + crypt hyperplasia (hyperplastic).

stage 3 lymphocytic enteritis + crypt hyperplasia + villous atrophy (destructive).

$3 a$ mild atrophy.

3b marked atrophy.

3c complete atrophy.

Stage 4 flat mucosa + crypt hypoplasia + mild inflammation ( atrophic).

Then by antiCD3 IHC study.

If 30 IELs and more positive for CD3, the case was considered positive.

If $26-29$ it is borderline.

If 25 and less it is negative ${ }^{8,9,15}$, and their distribution whether in crescendo pattern i.e. increased in number of IELs from the base to the tip of the villous or decrescendo pattern i.e. decrease in number of IELs from the base to the tip of the villous.

The distribution of CD3 positive IELs was noted whether diffused or patchy. Differentiation between surface CD3 and intracytoplasmic CD3 immune stain or both according to its distribution i.e. if it is global (the entire membrane of the CD3+ lymphocytes are of surface CD3 immune stain ) or clonal distribution (both partial membranous and intracytoplasmic CD3 immune stain $)^{3}$. 


\section{Statistical analysis}

This descriptive study for the collected data was analyzed using Statistical Package for Society Study (SPSS) statistical software version 19.0. Qualitative data were evaluated using the frequency and related percentage by using of Chisquare test and a $P$ value equal or less than 0.05 was considered statistically significant with confidence interval of $95 \%$.

\section{RESULTS}

Duodenal biopsies have been taken from 100 cases suspected to have CeD where their ages ranges between (1-69) years with a mean age of 20.74 years and median (17)years. Children represented $41(41 \%)$ of the sampled cases (27 female and 14 male) with a female to male ratio 1.9:1, while adult 59 (59\%) (42 female and 17 male) with a female to male ratio 2.4:1. Among the 100 cases, there were $69(69 \%)$ females and $31(31 \%)$ males, female : male ratio is (2.2:1).

By applying modified Marsh's classification on the mucosal changes by H\&E stain on 100 $(100 \%)$ cases: Marsh 0 was detected in 8 ( $8 \%)$ cases, Marsh 1 in 30 (30\%) cases, Marsh 2 in 10 $(10 \%)$ cases, while Marsh 3 a in $20(20 \%)$ cases, Marsh $3 \mathrm{~b}$ in $17(17 \%)$ cases, Marsh $3 \mathrm{c}$ in 15 $(15 \%)$ cases and Marsh $4: 0(0 \%)$, all stages of modified Marsh classification were shown in figure (1).

Lamina propria in cases with features of $\mathrm{CeD}$ shows mild-moderate or heavy infiltration of chronic inflammatory cells ( lymphocytes and plasma cells), and some of them associated with neutrophils and eosinophils.

The sex and age distribution of cases suspected $\mathrm{CeD}$ according to modified Marsh classification were shown in tables (1 and 2).

Immunohistochemical expression of CD3 in the sampled cases i.e. CD3 $+\geq 30$ IEL /100 epithelial cells were detected in 79 (79\%) cases. Seventeen out of 30 cases $(56.7 \%)$ that diagnosed Marsh 1 were CD3 + while 2 out of 30 cases were border line. The last 11 out of 30 cases were negative CD3 immune stain, as shown in table (3).

All the CD3 + cases that have been detected in $79(79 \%)$ cases are of crescendo pattern of distribution from the base to the tips of the villi while the border line and negative immune stain cases are of decrescendo pattern of distribution from the base to the tips of the villi, as shown in table (4).

The diffuse distribution of CD3+ intraepithelial lymphocytes along the villi was noted in 78 out of 79 cases of CD3 + cases, while only one case was observed with patchy distribution and associated with Helicobacter pylori infection, all stages of modified Marsh classification with CD3 IHC stain were shown in figure (2).

The distribution of staining of $\mathrm{CD} 3+$ intraepithelial lymphocytes was global surface $(\mathrm{sCD} 3+)$ in $98(98 \%)$ cases and clonal surface ( sCD3+) \& intracytoplasmic (iCD3 + ) in $<20 \%$ of IEL in $2(2 \%)$ cases, that need flowcytometric analysis to confirm the diagnosis of Refractory Celiac disease, was shown in table (5) and figure (3).

Age and sex distribution of CD3 + intraepithelial lymphocytes in cases suspected CeD were shown in tables (6 and 7).

Table 1: The sex distribution in cases suspected $\mathrm{CeD}$ according to modified Marsh classification $(\mathrm{N}=100)$ ( $P$ Value 0.005)

\begin{tabular}{|l|l|l|l|l|}
\hline Stage & Male & Female & Total & $\%$ \\
\hline 0 & 3 & 5 & 8 & $8 \%$ \\
\hline 1 & 8 & 22 & 30 & $30 \%$ \\
\hline 2 & 8 & 2 & 10 & $10 \%$ \\
\hline $3 a$ & 7 & 13 & 20 & $20 \%$ \\
\hline $3 b$ & 4 & 13 & 17 & $17 \%$ \\
\hline $3 c$ & 1 & 14 & 15 & $15 \%$ \\
\hline 4 & 0 & 0 & 0 & $0 \%$ \\
\hline
\end{tabular}

Table 2: The age distribution in cases suspected $\mathrm{CeD}$ according to modified Marsh classification $(\mathrm{N}=100)(P$ Value 0.081$)$.

\begin{tabular}{|l|l|l|l|l|}
\hline Stage & Children & Adult & Total & $\%$ \\
\hline 0 & 5 & 3 & 8 & $8 \%$ \\
\hline 1 & 11 & 19 & 30 & $30 \%$ \\
\hline 2 & 7 & 3 & 10 & $10 \%$ \\
\hline $3 a$ & 10 & 10 & 20 & $20 \%$ \\
\hline $3 \mathrm{~b}$ & 5 & 12 & 17 & $17 \%$ \\
\hline $3 \mathrm{c}$ & 3 & 12 & 15 & $15 \%$ \\
\hline 4 & 0 & 0 & 0 & $0 \%$ \\
\hline
\end{tabular}

Table 3: The count of CD3 + intraepithelial lymphocytes per 100 epithelial cells according to modified Marsh classification ( $\mathrm{N}=100)(P$ Value < 0.001).

\begin{tabular}{|l|l|l|l|l|}
\hline Stage & $\geq 30 / 100$ & $\begin{array}{l}26- \\
29 / 100\end{array}$ & $\leq 25 / 100$ & Total \\
\hline 0 & 0 & 0 & 8 & 8 \\
\hline 1 & 17 & 2 & 11 & 30 \\
\hline 2 & 10 & 0 & 0 & 10 \\
\hline $3 a$ & 20 & 0 & 0 & 20 \\
\hline $3 b$ & 17 & 0 & 0 & 17 \\
\hline $3 c$ & 15 & 0 & 0 & 15 \\
\hline 4 & 0 & 0 & 0 & 0 \\
\hline Total & 79 & 2 & 19 & 100 \\
\hline
\end{tabular}


Table 4: The distribution of CD3 + intraepithelial lymphocytes per 100 epithelial cells crescendo vs. decrescendo from the base to the tips of the villi $(\mathrm{N}=100)$.

\begin{tabular}{|l|l|l|l|l|}
\hline Distribution & $\geq$ & $26-$ & $\leq$ & Total \\
& $30 / 100$ & $29 / 100$ & $25 / 100$ & \\
\hline Decrescendo & 0 & 2 & 19 & 21 \\
\hline Crescendo & 79 & 0 & 0 & 79 \\
\hline Total & 79 & 2 & 19 & 100 \\
\hline
\end{tabular}

Table 5: The distribution of staining of CD3 + intraepithelial lymphocytes according to modified Marsh classification $(\mathrm{N}=100)$.

\begin{tabular}{|l|l|l|l|l|}
\hline Stage & $\begin{array}{l}\text { Global } \\
\text { sCD3 }+\end{array}$ & $\begin{array}{l}\text { Clonal } \\
\text { sCD3 }+ \\
\& \text { iCD3 }+ \\
<20 \%\end{array}$ & $\begin{array}{l}\text { Clonal } \\
\text { sCD3 }+ \\
\& \text { iCD3 } \\
+>20 \%\end{array}$ & Total \\
\hline 0 & 8 & 0 & 0 & 8 \\
\hline 1 & 30 & 0 & 0 & 30 \\
\hline 2 & 10 & 0 & 0 & 10 \\
\hline $3 a$ & 20 & 0 & 0 & 20 \\
\hline $3 b$ & 17 & 0 & 0 & 17 \\
\hline $3 c$ & 13 & 2 & 0 & 15 \\
\hline 4 & 0 & 0 & 0 & 0 \\
\hline Total & 98 & 2 & 0 & 100 \\
\hline
\end{tabular}

Table 6: The age distribution of CD3 + intraepithelial lymphocytes in cases suspected $\operatorname{CeD}(\mathrm{N}=100)$.

\begin{tabular}{|l|l|l|l|l|}
\hline Age & $\begin{array}{l}\text { CD3 + } \\
\geq 30 / 100\end{array}$ & $\begin{array}{l}\text { CD3 + } \\
26- \\
29 / 100\end{array}$ & $\begin{array}{l}\text { CD3 + } \\
\leq 25 / 100\end{array}$ & Total \\
\hline $\begin{array}{l}\text { Children } \\
<15 \\
\text { years }\end{array}$ & 33 & 0 & 8 & 41 \\
\hline $\begin{array}{l}\text { Adult } \\
\geq 15 \\
\text { years }\end{array}$ & 46 & 2 & 11 & 59 \\
\hline Total & 79 & 2 & 19 & 100 \\
\hline
\end{tabular}

Table 7: The sex distribution of CD3 + intraepithelial lymphocytes in cases suspected CeD $(\mathrm{N}=100)$.

\begin{tabular}{|l|l|l|l|l|}
\hline Sex & $\begin{array}{l}\text { CD3 }+ \\
\geq 30 / 100\end{array}$ & $\begin{array}{l}\text { CD3 }+ \\
26- \\
29 / 100\end{array}$ & $\begin{array}{l}\text { CD3 }+ \\
\leq 25 / 100\end{array}$ & Total \\
\hline Male & 27 & 0 & 4 & 31 \\
\hline Female & 52 & 2 & 15 & 69 \\
\hline Total & 79 & 2 & 19 & 100 \\
\hline
\end{tabular}
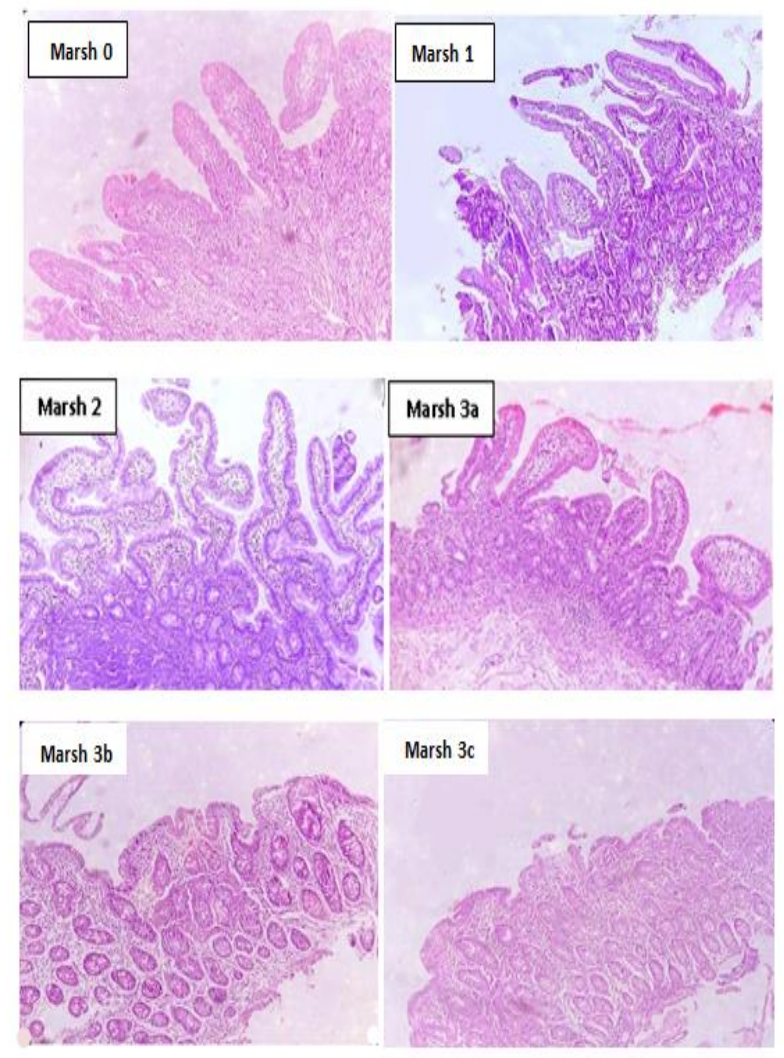

Figure 1: duodenal biopsies stained by H\&E stain $X 40$ show all stages of modified Marsh classification.

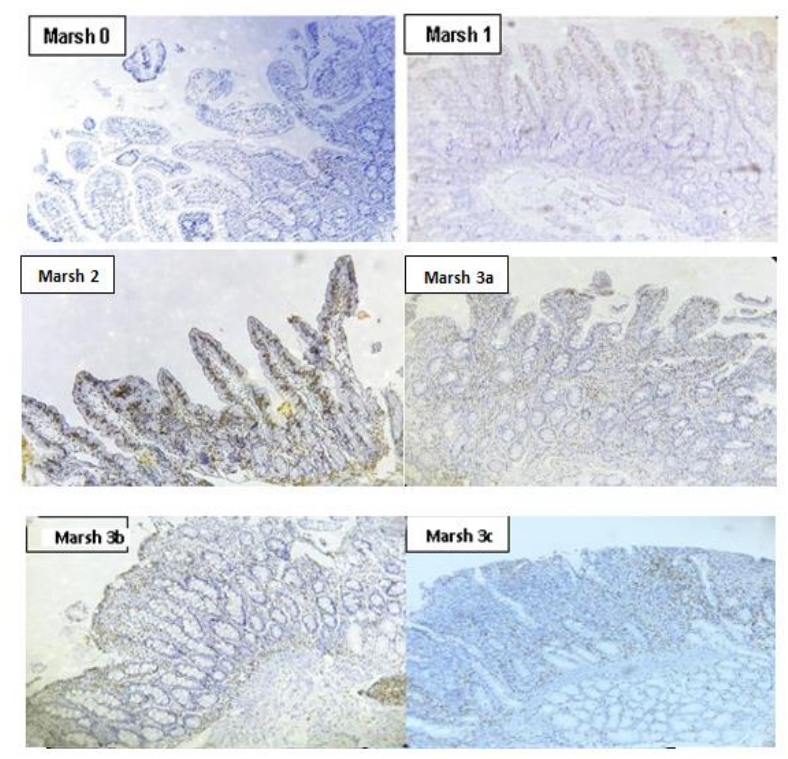

Figure 2: duodenal biopsies CD3 IHC stain X40 in relation to modified Marsh classification. 


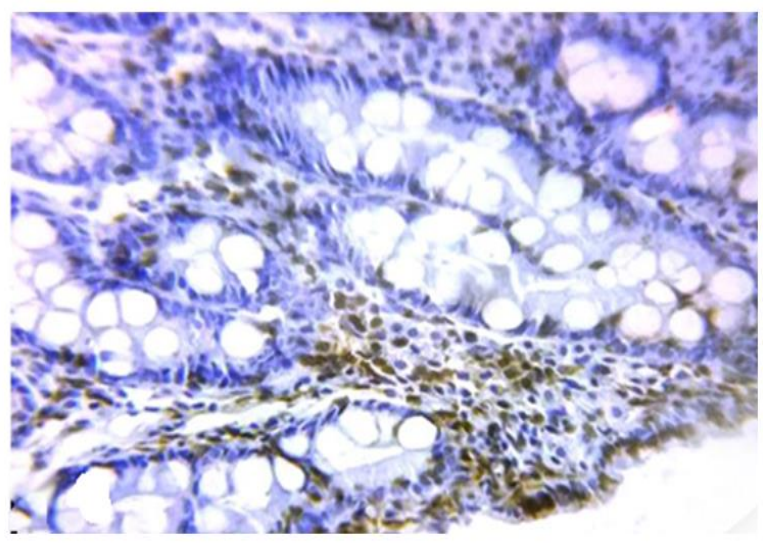

Figure 3: duodenal biopsy CD3 IHC stain X100 in Marsh 3c shows clonal CD3 (sCD3 and iCD3 < $20 \%$ ) of intraepithelial lymphocytes.

\section{DISCUSSION}

Until now the duodenal biopsy is still necessary and remains the gold standard for the diagnosis and follow up of patients with $\mathrm{CeD}$, which is usually supplemented by serologic tests ${ }^{4,16}$. Accordingly, apart from grading villous atrophy and crypt hyperplasia, the assessment of IELs is essential and regarded as a key for the correct diagnosis of $\mathrm{CeD}$ in early stages (Marsh 1) ${ }^{17}$ because sometimes the contrast between the blue color of lymphocyte nucleus and epithelial cell nucleus is inconclusive by H\&E stain ${ }^{18,19}$.

Therefore, the use of more sophisticated method such as IHC to differentiate intraepithelial lymphocytes from epithelial cells is essential. As IELs are CD3 positive cells, performing IHC staining against CD3 can aid in estimating the exact number and the distribution of IELs more precisely than using conventional histological stain (H\&E) ${ }^{6}$.

\section{Age and Gender}

In the current study among 100 cases suspected to have $\mathrm{CeD}$ and underwent endoscopic biopsy. Children $<15$ years old represented $41 \%$ of the sampled cases ,while adults $\geq 15$ years old were $59 \%$, which reflects that adults are affected by $\mathrm{CeD}$ more than children. Previously, CeD was considered a disease of childhood because the majority of the cases were less than 2 years of age ${ }^{20-22}$. However, the disease is common in adults and can be diagnosed at any age ${ }^{18}$. Radlovic ,2013 in Serbia ${ }^{20}$ mentioned that the classical form of the disease is mainly seen in infants and children and atypical in later ages and in adults. Some studies were found that its frequency is twice in children than in adults ${ }^{20-22}$ while others showed adult prevalence become more frequent, sometimes reaching similar $7,18,19$. This attributed to various environmental factors in addition to age of introduction of gluten and the amount of it in the food, which have been implicated in the pathogenesis of $\mathrm{CeD}{ }^{21}$. In the present study the discrepancy in the age of the sampled cases may due to the recording center that focused on an adult more than pediatric population during sample collection.

Gender distribution is variable in different parts of the world, some geographical areas show equal division in both sexes, while others are more to one of them ${ }^{3,12,18,23}$. In the present study, there were $69 \%$ females and $31 \%$ males, with female to male ratio is (2.2:1). This finding was observed in many studies $1,3,7,19,24,25$. While other study done by Iftikhar et al.,2016 in Pakistan ${ }^{12}$ show that $84 \%$ of the cases were males and $16 \%$ of the cases were females.

The differential rates of diagnosis among gender is thought to reflect several factors, such as hormonal factor, a higher rate of autoimmune disease among women in general, more regular health care interaction in female than male subjects and a higher likelihood of symptomatic disease among women than men ${ }^{21,26,27}$.

\section{Histological analysis of duodenal biopsy}

Modified Marsh classification was valuable for diagnostic purposes and for follow up of patients with $\mathrm{CeD}$ by assessing the histologic recovery in response to gluten withdrawal. This can be accomplished by reviewing the previous histological report and comparing it with the present report, this will give an idea about the progress of $\mathrm{CeD}$ and extent of response to gluten challenge ${ }^{28}$.

In this study and according to modified Marsh classification which is used by many studies $8,9,12,15$ on the mucosal changes by H\&E stain on 100 cases, Marsh 0 was detected in $8 \%$ of the cases and considered as chronic nonspecific duodenitis, while another study done in Turkey by Sezgin et al.,2016 ${ }^{18}$ showed that half of the cases were Marsh 0, on the other hand, Paul. et al.,2019 ${ }^{5}$ was detected Marsh 0 in $70 \%$ of the cases. While Shihab \& Enaya,2020 ${ }^{19}$ in their study in south of Iraq, Marsh 0 was not detected, this difference depends on the awareness of the population to the disease and the availability of the diagnostic facilities ${ }^{12,18}$.

Marsh 1 was observed in $30 \%$ of the sampled cases. This finding is within the range of that observed by Brown et al.,2006 ${ }^{17}$ and Lauwers et al.,2015 ${ }^{10}$ studies in which Marsh 1 were noted in 
9-40\% of the cases, while higher than those noted by other studies such as Hammer \& Greenson,2013 ${ }^{29}$ who were detected Marsh 1 in $1-3 \%$ of the cases, Iftikhar et al.,2016 ${ }^{12}$ in $22 \%$ of the cases and Paul et al.,2019 ${ }^{5}$ in $19 \%$ of the cases.

The exact prevalence of Marsh 1 is difficult to determine because there are many causes of increased IELs with normal villous architecture ${ }^{17}$. So, an increase in IELs infiltration alone in duodenal biopsies (Marsh 1) is not specific for $\mathrm{CeD}$ and other causes should be excluded like Helicobacter pylori, Giardia lamblia, cryptosporidium and others ${ }^{3}$. Thus, negative serology does not exclude a diagnosis of $\mathrm{CeD}$ with a Marsh 1 pattern, a morphologic evaluation remains essential ${ }^{10}$.

In the present study, crypt hyperplasia observed in $62 \%$ (Marsh 2 and Marsh 3) while in Iftikhar et al.,2016 ${ }^{12}$ study noted in $78 \%$.

Villous atrophy (Marsh 3) was observed in 52\% of the current study, while in Iftikhar et al.,2016 ${ }^{12}$ study was $74 \%$ of the cases.

In Turkey Sezgin et al.,2016 ${ }^{18}$ found that half of the cases in their study was Marsh 2 and 3, while Paul found in $11 \%$ of the cases Marsh 2 and $3^{5}$. These differences may be due to the fact that in Iraq, the patients generally do not seek medical advice early and this may be due to poverty, illiteracy and parents negligence and therefore, there is a delay of patients attendance to clinical observation ${ }^{30}$. Moreover, patients with $\mathrm{CeD}$ have a long duration of symptoms and may see many physicians before diagnosis by duodenal biopsy. As a result, there is a high rate of dissatisfaction about this diagnostic delay that is physician based. Failure of physician to recognize the diverse clinical presentation of $\mathrm{CeD}$, less awareness of disease among clinicians as well as for quality of diagnostic tools and their availability contributes to the diagnostic delay ${ }^{31}$. Also CeD regarded as difficult to be diagnosed because of the alternative diagnosis (often irritable bowel syndrome), in addition to the diversity of symptoms and even sometimes associated with a period of latency. Some physicians are unaware of the condition and there are several "myths," such as CeD is rare, occurs in Caucasians, it is mostly in Europe and the United States, it is disease of childhood, it occurs only with chronic diarrhea and it can be cured after a period of treatment ${ }^{32}$.

Marsh 4 was not detected in the present study. This finding is in agreement with that observed by Dickson and his colleagues, $2006{ }^{33}$ who consider Marsh stage 4 is a rare stage of the disease.

\section{CD3 immunohistochemical stain}

The use of CD3 IHC expression in the sampled cases of the present study represents a sensitive and specific tool to distinguish IELs from epithelial cells ${ }^{19}$ especially in Marsh 1 cases because the occurrence of IELs by itself is not specific for $\mathrm{CeD}$ and can be observed in forms of intestinal inflammations ${ }^{34}$ or other causes ${ }^{35,36,37}$. Therefore the presence of IELs should be seriously taken into consideration.

In the current study, CD3 positive cases i.e. CD3 $+\geq 30$ IEL /100 epithelial cells were detected in $79 \%$ of the cases and this result within the results of other studies, as Shihab \& Enaya, 2020 19 in the South of Iraq were $100 \%$, Iftikhar et al., $2016^{12}$ in Pakistan were $100 \%$ and Mubarak et al., $2015^{6}$ in Netherland were $68.55 \%$.

This variation in the percentage of CD3 positive cases of these studies may be due to variation in the IHC staining technical operation with different manufacturers, variation of kits and types of antibodies which were used, genetic and environmental factors, in addition to the variation of patient's age group.

Mubarak et al.,2015 ${ }^{6}$ study showed that from $40.88 \%$ of the cases with Marsh 0 by H\&E, only $10.69 \%$ of the cases show positive results by CD3 immune stain, and out of $3.77 \%$ of the cases diagnosed as Marsh 1 by H\&E, $0.62 \%$ of the cases was negative CD3 immune stain and $55.34 \%$ of the cases Marsh 2 \& 3 only $0.62 \%$ was negative CD3 immune stain.

Iftikhar et al.,2016 12 study on histomorphological and immuno-histochemical analysis of small intestinal biopsies in adults suspected of CeD, as they count IELs both by $\mathrm{H} \& \mathrm{E}$ stain and immune stain CD3 and CD20; found that CD3 immune marker was positive for IELs in all cases establishing the fact that IELs were of T-cell origin, while CD20 immune marker (B-lymphocytes) have shown the focal positivity in areas with lymphoid follicle formation with germinal center.

Shihab \& Enaya,2020 ${ }^{19}$ study on 60 cases, CeD was confirmed by both the routine histopathological examination and immunohistochemical analysis in all cases.

All of CD3 positive cases in the present study were crescendo pattern of distribution from the base to the tip of the villi. The same result was obtained by Iftikhar et al.,2016 ${ }^{12}$ in Pakistan and by Shihab \& Enaya $2020^{19}$ in the south of Iraq.

In this study $30 \%$ out of 100 cases diagnosed as Marsh 1 by H\&E, 17 out of 30 cases (56.7\%) were CD3+ positive and they were in crescendo pattern while 11 cases CD3+ less than or equal to $25 / 100$ epithelial cells and of decrescendo pattern. The last two cases were border line and 
of decrescendo pattern i.e. regarded negative for CD3 immune stain as the distribution pattern of IELs within the epithelium is more valuable than the actual counts $8,10,11,15$. So 13 out of 30 cases Marsh 1 regarded negative for $\mathrm{CeD}$ after CD3 immune stain. While Goldstein N.S.\& Underhill J.,2001 ${ }^{24}$ in their study on cases with potential $\mathrm{CeD}$ noticed that 9 out of 12 cases with CeD were of crescendo pattern of distribution from the base to the tip of the villi . On the other hand, in Iftikhar et al.,2016 ${ }^{12}$ study showed all the CD3 positive cases were in crescendo pattern also.

In the present study, the CD3 + IELs in duodenal biopsy was distributed diffusely and in crescendo pattern from the base of the villi to the tip in all cases except one case that is of patchy distribution and associated with H.pylori. This finding was also observed by Shihab`s study ${ }^{19}$.

The IHC expression of CD3 marker plays an important role in the diagnosis of early stage of $\mathrm{CeD}$ (Marsh 1) which is if misdiagnosed as chronic inflammatory changes by H\&E and not treated as $\mathrm{CeD}$, it can therefore develop into overt CeD with the passage of time ${ }^{38,39}$.

So, this study showed that in compared to $H \& E$ stains alone, CD3 immune stains could lead to definite assessment in $13 \%$ of cases with Marsh 1.This observation was also noted by a study done by Mubarak and colleagues who showed that compared to H\&E stain, CD3 immune stains could lead to definite assessments in $12.6 \%$ of cases ${ }^{6}$.

The IHC expression of CD3+ marker provides a hint about the distribution of CD3+ marker within the lymphocyte whether global surface or clonal surface and intracytoplasmic to diagnose Refractory $\mathrm{CeD}$ and differentiate between its two types because type II may precede EATL ${ }^{1,4}$.

In the current study, it is difficult to differentiate surface CD3 from intracytoplasmic CD3 exactly by CD3 immune stain only. Flowcytometric analysis is better for this situation ${ }^{4,40}$, as it is regarded the gold standard for the detection of aberrant phenotype of IELs ${ }^{13,14,41}$.

\section{CONCLUSION}

There is a significant relationship between the count of CD3+ T-lymphocytes per 100 epithelial cells and the histopathological changes in the duodenal biopsy according to modified Marsh classification. So, the immunohistochemical expression of $\mathrm{CD} 3$ in intraepithelial T-lymphocyte could lead to a definite assessment in $43.3 \%$ of the sampled cases with Marsh type 1. All the positive cases are of crescendo pattern of distribution of CD3+ T-lymphocytes as the distribution is more important than the actual count and they distributed diffusely except that associated with $\mathrm{H}$. pylori infection observed with patchy distribution. In addition to that, The IHC expression of $\mathrm{CD} 3+$ marker provides a hint about the distribution of CD3+ marker within the lymphocyte whether global surface or clonal surface and intracytoplasmic to diagnose Refractory Celiac disease.

On the other hand, females were more affected than males with $\mathrm{CeD}$ and there is a significant relationship between the gender of the sampled cases and the histopathological changes in the duodenal biopsy.

The disease can be diagnosed at any age and there is no significant relationship between the age distribution of the sampled cases and the histopathological changes in the duodenal biopsy.

\section{REFERENCES}

1.Gujral N., Freeman H.J. Thomson A.B. Celiac disease: prevalence, diagnosis, pathogenesis and treatment. World J Gastroenterol, 2012. 18: 6036-59.

2. Nardecchia S., Auricchio R., Discepolo V. Troncone R. Extra-Intestinal Manifestations of Coeliac Disease in Children: Clinical Features and Mechanisms. Front Pediatr, 2019.7: 56.

3. Caio G., Volta U., Sapone A., Leffler D.A., De Giorgio R., Catassi C., et al. Celiac disease: a comprehensive current review. BMC Med, 2019.17: 142.

4.Al-Toma A., Volta U., Auricchio R., Castillejo G., Sanders D.S., Cellier C., et al. European Society for the Study of Coeliac Disease (ESsCD) guideline for coeliac disease and other gluten-related disorders. United European Gastroenterol J, 2019.7: 583-613.

5. Paul B., Kinra P., Nandi B. Prasad AS. Correlation of serum tissue transglutaminase antibody levels and marsh grading of duodenal biopsy in patients of Celiac disease. Annals of Path and Lab. Med., 2019. 6:141-8.

6. Mubarak A., Wolters V.M., Houwen R.H. ten Kate F.J. Immunohistochemical CD3 staining detects additional patients with celiac disease. World J Gastroenterol, 2015. 21: 7553-7.

7.Hashim Z.A., AL-Namil S.A., Jazi W.M. Strak S.K. The value of endoscopic biopsies from first and second parts of the duodenum in the diagnosis of Celiac disease in correlation with serological test. Bas J Surg. 2017. 23: 34-9.

8. Robert M.E., Crowe S.E., Burgart L., Yantiss R.K., Lebwohl B., Greenson J.K., et al. Statement on Best Practices in the Use of Pathology as a Diagnostic Tool for Celiac Disease: A Guide for Clinicians and 
Pathologists. Am J Surg Pathol, 2018. 42: e44e58.

9.Serra S. \& Jani P.A. An approach to duodenal biopsies. J Clin Pathol, 2006. 59: 1133-50.

10. Lauwers G.Y., Fasano A. Brown I.S. Duodenal lymphocytosis with no or minimal enteropathy: much ado about nothing. Mod Pathol, 2015.28 Suppl 1: S22-9

11. Ensari A. Gluten-sensitive enteropathy (celiac disease): controversies in diagnosis and classification. Arch Pathol Lab Med, 2010. 134: 826-36.

12. Iftikhar R., Jamal S., Zafar A. Saadia A. Histopathological and Immunohistochemical Analysis of Small Intestinal Biopsies in Adults Suspected of Celiac Disease. J Coll Physicians Surg Pak, 2016. 26: 827-30.

13. Van Wanrooij R.L., Müller D.M., Neefjes-Borst E.A., Meijer J., Koudstaal L.G., Heideman D.A., et al. Optimal strategies to identify aberrant intra-epithelial lymphocytes in refractory coeliac disease. J Clin Immunol, 2014.34: 828-35.

14. Hujoel I.A. \& Murray J.A. Refractory Celiac Disease. Curr Gastroenterol Rep, 2020. 22: 18.

15. Sergi C., Shen F. \& Bouma G. Intraepithelial lymphocytes, scores, mimickers and challenges in diagnosing gluten-sensitive enteropathy (celiac disease). World J Gastroenterol 2017;23: 573-89.

16. Shehab D.I. Celiac disease.The Egypt Soc of Int Medicine, 2013. 25:53-62.

17. Brown I., Mino-Kenudson M., Deshpande V. Lauwers G.Y. Intraepithelial lymphocytosis in architecturally preserved proximal small intestinal mucosa: an increasing diagnostic problem with a wide differential diagnosis. Arch Pathol Lab Med, 2006.130: 1020-5.

18. Sezgin O., Saritas B., Aydin I., Sasmaz T. Linke E. Celiac disease prevalence in Turkey: A population based cross-sectional study. Acta M. Mediterranea, 2016. 32: 463.

19. Shihab M.A. Enaya H.M. Immunohistochemical evaluation of CD3 T-cell lymphocyte and CD20 B-cell markers in Iraqi patients with Celiac disease. EurAs J Bio, 2020.14: 2023-8.

20. Radlović N. Celiac disease. Srp Arh Celok Lek, 2013.141: 122-6.

21. Green P.H., Lebwohl B., Greywoode R. Celiac disease. J. Allergy Clin. Immunol. 2015.135:1099-106.

22. Sánchez-Castañon M., Castro B.G., Toca M. Santacruz C., Arias-Loste M., Iruzubieta P., et al. Intraepithelial lymphocytes subsets in different forms of celiac disease. Auto Immun Highlights, 2016.7: 14.

23. Rostami Nejad M., Rostami K., Emami M., Zali M. Malekzadeh R. Epidemiology of celiac disease in Iran: a review. Middle East J Dig Dis, 2011.3: 5-12.

24. Goldstein N.S. Underhill J. Morphologic features suggestive of gluten sensitivity in architecturally normal duodenal biopsy specimens. Am J Clin Pathol, 2001.116: 63-71.

25. Tye-Din J.A., Galipeau H.J. Agardh D. Celiac Disease: A Review of Current Concepts in Pathogenesis, Prevention, and Novel Therapies. Front Pediatr, 2018. 6: 350.

26. Bardella M.T., Fredella C., Saladino V., Trovato C., Cesana B.M., Quatrini M., et al. Gluten intolerance: gender- and age-related differences in symptoms. Scand J Gastroenterol, 2005.40: 15-9.

27. Jansson-Knodell C.L., King K.S., Larson J.J., Van Dyke C.T., Murray J.A. Rubio-Tapia A. Gender-Based Differences in a PopulationBased Cohort with Celiac Disease: More Alike than Unalike. Dig Dis Sci, 2018. 63: 184-92.

28. Wahab P.J., Meijer J.W. Mulder C.J. Histologic follow-up of people with celiac disease on a gluten-free diet slow and incomplete recovery. Am J Clin Pathol, 2002. 118:459-63.

29. Hammer S.T. Greenson J.K. The clinical significance of duodenal lymphocytosis with normal villus architecture. Arch Pathol Lab Med, 2013.137: 1216-9.

30. Zahra T., Memon A. Afsar S. Celiac disease. Pak Med Sci, 2005. 21:225-7.

31. Peter H. Josef A. Routine duodenal biopsies to exclude celiac disease.Gastrointest endos , 2003.58:92-5.

32. Bai J.C., Fried M., Roberto G., Schuppan D., Farthing M., Catassi C. et al. Celiac disease. WGO Global Guidelines, 2012. 6:14-5.

33. Dickson B.C., Streutker C.J. Chetty R. Coeliac disease: an update for pathologists. $J$ Clin Pathol, 2006. 59: 1008-16.

34. Husby S., Koletzko S., Korponay-Szabó I.R., Mearin M.L., Phillips A., Shamir R., et al. European Society for Pediatric Gastroenterology, Hepatology, and Nutrition guidelines for the diagnosis of coeliac disease. J Pediatr Gastroenterol Nutr, 2012. 54: 136-60.

35. Konturek P.C., Karczewska E., Dieterich W., Hahn E.G. Schuppan D. Increased prevalence of Helicobacter pylori infection in patients with celiac disease. Am J Gastroenterol , 2000. 95: 3682-r.

36. Memeo L., Jhang J., Hibshoosh H., Green P.H., Rotterdam H. Bhagat G. Duodenal intraepithelial lymphocytosis with normal villous architecture: common occurrence in $\mathrm{H}$. pylori gastritis. Mod Pathol , 2000.18: 1134-44.

37. Maxim R., Pleşa A., Stanciu C., Girleanu I., Moraru E. Trifan A. Helicobacter pylori 
prevalence and risk factors among children with celiac disease. Turk J Gastroenterol, 2019. 30:284-9.

38. Kurppa K., Ashorn M., Iltanen S., Koskinen L.L., Saavalainen P., Koskinen O., et al. Celiac disease without villous atrophy in children: a prospective study. J Pediatr, 2019.157: 373-80.

39. Dabbas D.J. Diagnostic immunohistochemistry: theranostic and genomic applications. $5^{\text {th }}$ ed, 2019; 520.

40. Aoyama Y., Tsunemine H., Zushi Y., Maruoka H., Goto Y., Kodaka T., et al. Colonal monomorphic epitheliotropic intestinal T-cell lymphoma with novel phenotype of cytoplasmic CD3 expression. J Clin Exp Hematop , 2019. 58: $102-6$.

41. El Hentati F.Z., Gruy F., lobagiu C. Lambert C. Variability of CD3 membrane expression and $\mathrm{T}$ cell activation capacity. Cytometry B Clin Cytom , 2019.78: 105-14. 